\title{
Human ocular filariasis: further evidence on the zoonotic role of Onchocerca lupi
}

\author{
Domenico Otranto $^{1 *}$, Filipe Dantas-Torres ${ }^{1,2}$, Zafer Cebeci $^{3}$, Baris Yeniad ${ }^{3}$, Nesimi Buyukbabani ${ }^{4}$, \\ Ozden Buyukbaba Boral ${ }^{5}$, Andrea Gustinelli ${ }^{6}$, Trimèche Mounir ${ }^{7}$, Yasen Mutafchiev ${ }^{8}$ and Odile Bain ${ }^{9}$
}

\begin{abstract}
Background: Among ocular vector-borne pathogens, Onchocerca volvulus, the agent of the so-called "river blindness", affects about 37 million people globally. Other Onchocerca spp. have been sporadically reported as zoonotic agents. Cases of canine onchocerciasis caused by Onchocerca lupi are on the rise in the United States and Europe. Its zoonotic role has been suspected but only recently ascertained in a single case from Turkey. The present study provides further evidence on the occurrence of O. lupi infesting human eyes in two patients from Turkey (case 1) and Tunisia (case 2). The importance of obtaining a correct sample collection and preparation of nematodes infesting human eyes is highlighted.

Methods: In both cases the parasites were identified with morpho-anatomical characters at the gross examination, histological analysis and anatomical description and also molecularly in case 1.

Results: The nematode from the first case was obviously $O$. lupi based on their morphology at the gross examination, histological analysis and anatomical description. In the second case, although the diagnostic cuticular characters were not completely developed, other features were congruent with the identification of $O$. lupi. Furthermore, the morphological identification was also molecularly confirmed in the Turkish case.

Conclusions: The results of this study suggest that $O$. lupi infestation is not an occasional finding but it should be considered in the differential diagnosis of other zoonotic helminths causing eye infestation in humans (e.g., D. immitis and Dirofilaria repens). Both cases came from areas where no cases of canine onchocerciasis were previously reported in the literature, suggesting that an in depth appraisal of the infestation in canine populations is necessary. Physicians and ophthalmologists are advised on how to preserve nematode samples recovered surgically, to allow a definitive, correct etiological diagnosis.
\end{abstract}

Keywords: Onchocerca lupi, Zoonosis, Ocular infestation, Dog, Turkey, Tunisia

\section{Background}

Many species of helminths may cause human blindness in developed and developing countries, and some of them still represent a major threat for public health [1]. This is the case of the so-called "river blindness" by Onchocerca volvulus (Spirurida, Onchocercidae), which affects about 37 million people [2] in East and West Africa as well as in central and South America [3]. In this case, visual impairment and blindness is mostly a direct effect of host immune response to microfilariae, which are released by female adult worms in the subcutaneous

\footnotetext{
* Correspondence: d.otranto@veterinaria.uniba.it

'Dipartimento di Sanità Pubblica Veterinaria e Zootecnia, Università degli

Studi di Bari, Bari Valenzano, Italy

Full list of author information is available at the end of the article
}

tissues. Conversely, the adult stage of other helminth species (e.g., Brugia spp., Thelazia spp., Dirofilaria spp., and Wuchereria spp.) may infest human eyelids, conjunctival sacs, lachrymal glands and, in some cases, the ocular globe.

Filarioids are parasites that also infest the human eye and, besides these species exclusively infesting humans (e.g., Wuchereria bancrofti, Brugia malayi and Loa loa), others of domestic and wild mammals are regarded as zoonotic agents (e.g., Dirofilaria spp., Onchocerca spp., Molinema spp., Brugia spp., and Pelecitus sp.) [4-7]. The life cycles and the animal reservoir hosts for many of these species are still poorly known. This is the case of Onchocerca lupi, a parasite described in the periocular

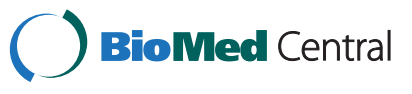


tissues of a Caucasian wolf (Canis lupus) in Georgia [8] that remained unknown for decades. The identification of the nematode as $O$. lupi had been attributed to a technical error (mislabelling of the specimen) or to a case of aberrant infestation, mainly because of the 'unusual' finding of a parasitic nematode specific to ungulates in a canid host. However, O. lupi types were re-examined $[9,10]$, the error relative to the size of microfilariae corrected (it is $100 \mu \mathrm{m}$ long, by far the smallest in the genus), and the validity of the species was also confirmed molecularly [11]. In dogs, cases of ocular onchocerciasis have been reported in Southern (Greece, Portugal) and Central Europe (Germany, Hungary, Portugal, Switzerland) [12-16]. Since the first case of canine onchocercosis recorded in western USA [17], all the following cases [18-20] were tentatively reported as an aberrant/occasional localization of parasite of cattle, horse or wild ungulates. However, Egyed et al. [11] argued that the parasites described in USA were similar to O. lupi, a conclusion only recently confirmed molecularly, in two cats [21]. O. lupi induces acute or chronic ocular disease in dogs, characterized by conjunctivitis, photophobia, lacrimation, ocular discharge and exophthalmia [22]. In humans, two ocular infestations by $O$. lupi have been suspected [23] and, recently, this species has been unambiguously identified in Turkey as causative agent of ocular infestation in a patient who exhibited clinical features similar to those of canine infestation [24].

Several Onchocerca species are agents of zoonoses. Among the 15 clinical cases of zoonotic onchocerciasis reported worldwide [22,25], the species identified were Onchocerca gutturosa [6] and Onchocerca cervicalis [26], affecting cattle and horses, respectively, Onchocerca jakutensis from the European deer [27] and, in half of the human cases, Onchocerca dewittei japonica from wild boar, reported only in Japan over the last 20 years [25]. Nonetheless, to the best of our knowledge, only O. gutturosa and O. cervicalis presented an ocular localization, whereas other species were detected mostly in the subcutaneous tissues. Information on the ocular zoonosis due to O. lupi remains meagre and whether the human case above was an occasional finding is unclear.

The present study describes the occurrence of $O$. lupi infesting the human eye in two patients, from Turkey and from Tunisia where onchocerciasis caused by $O$. lupi has never been reported in dogs. In both cases, the nematode was erroneously identified either as Dirofilaria immitis [28] or as a suspected Dirofilaria sp. (Zafer Cebeci, pers. com.), respectively. The main gross morphological and histological features of this parasite have been discussed here as well as the relevance of appropriate sample collection and preparation, instrumental to a correct diagnosis of nematodes infesting the human eye. The parasites were identified morphologically and also molecularly in the Turkish case.

\section{Methods}

\section{Clinical history}

A 26 year old male patient (case 1) was admitted to the Department of Ophthalmology of the Hospital of the Istanbul Faculty of Medicine (Turkey), presenting irritation and itchiness of the right eye. The patient lived in Istanbul (Turkey, $41^{\circ} 1^{\prime} \mathrm{N}, 28^{\circ} 57^{\prime} \mathrm{E}$ ) and had never travelled abroad except to Antalya (Turkey, 39 $53^{\prime} \mathrm{N} 30^{\circ} 42^{\prime}$ E) where he spent ten days of vacation, during the previous summer (June, 2011). The patient experienced a "growing redness" nasally to the right eye for two weeks. The orbital CT at the lesion site showed an increase in density of soft tissues but no foreign bodies. On admission the visual acuity was $10 / 10$ for both eyes with no alterations of the left eye. The right eye showed a normal presentation except for $5 \times 5 \mathrm{~mm}$ swelling and a conjunctiva mass in the nasal conjunctiva region. Topical corticosteroid (Prednisolone 1\% acetate, Allergan inc.) and antibiotics (Tobramicina, Tobrased, Bilim), 4 drops per day and systemic antibiotics (Ciprofloxacin $500 \mathrm{mg}$, Biofarma), twice a day were administered, for one week. After one week no clinical improvement was observed and the presence of a foreign body was suspected, thus explorative surgery was undertaken. At the conjunctiva excision (Figure 1A) of the fibrous mass, filamentous tiny nematodes were observed tightly beneath the subconjunctiva and promptly extracted. The parasite was cohesive to the surrounding tissue and to thick fibrous tissue around. A partial 'scleral invasion' was suspected but the fundoscopic examination was normal before and after the surgery. These fragments of nematodes, overall measuring $10 \mathrm{~cm}$ in length, were extracted and delivered to the Parasitology Department of the same University, where it was tentatively identified as Dirofilaria repens.

In case 2, described in Ziadi et al. [28], the extracted parasite was erroneously identified as D. immitis. Briefly, the patient was an 8-year old child referred to the Service d'Ophtalmologie, Farhat Hached, Tunis (Tunisia), the child had been suffering from a fastidious pain of the right eye for four weeks. The patient lived in the region of Kasserine (west-central of Tunisia, $35^{\circ} 10^{\prime} \mathrm{N}, 8^{\circ} 50^{\prime} \mathrm{E}$ ), which is at the centre of an irrigated agricultural area, and had never travelled abroad or to other areas. At the medical examination a subconjunctival mass $(0.8 \mathrm{~cm}$ in diameter) was observed and immediately surgically excised and delivered to the Laboratoire d'Anatomie et de Cytologie Pathologiques, of the same Hospital for examination. Differently from case 1, along with the parasite, host tissues around the nematode were extracted from subconjunctiva and processed histologically. Following the request of one of the authors (O.B.) the histology of paraffin block 

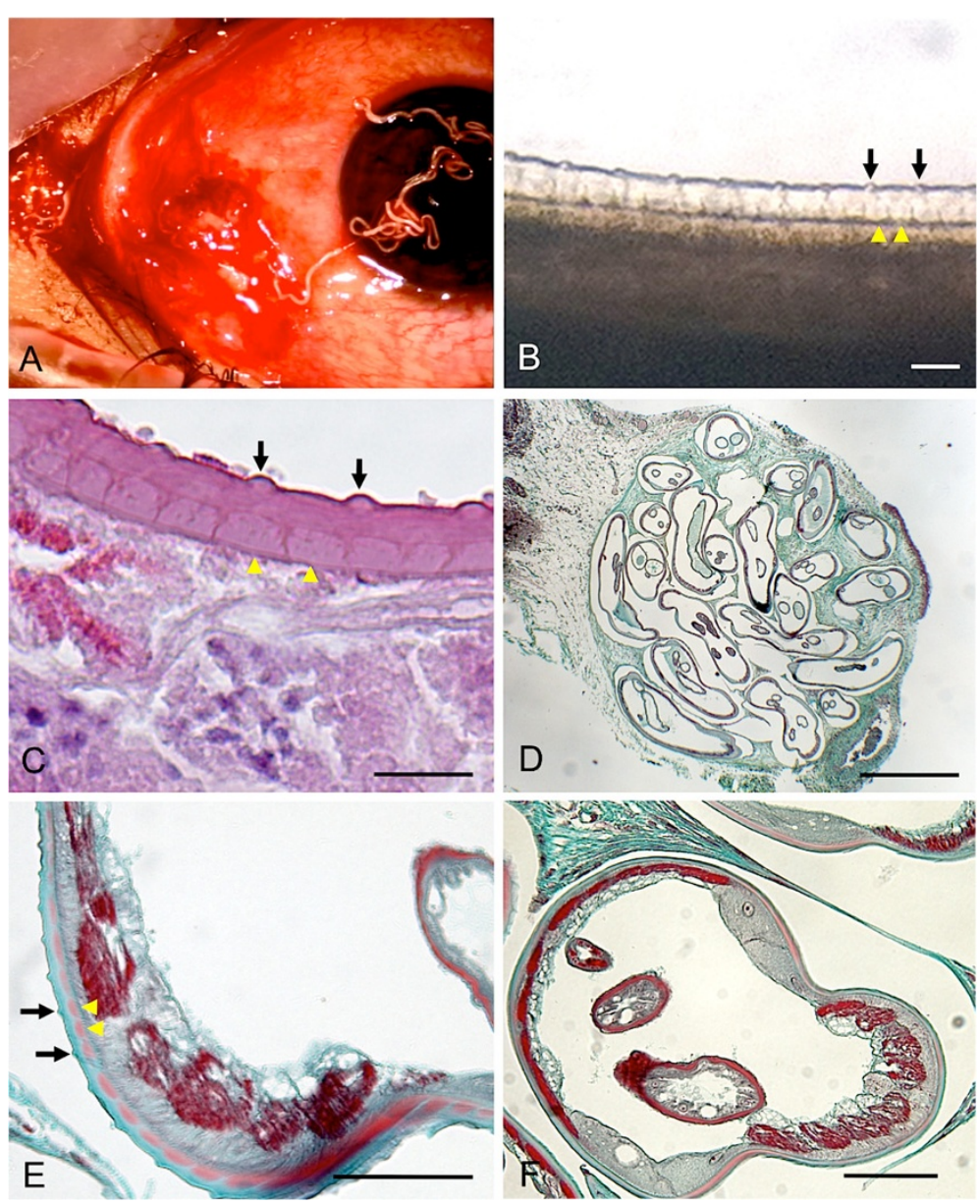

Figure 1 A-C (case 1). A, Conjunctiva excision of the fibrous mass tissue with the extracted nematode tightly beneath the sub-conjunctiva. B and C: Longitudinal view of the cuticle of the nematode before fixation (B) and after haematoxylin and eosin staining showing the external prominent ridges (black arrows) and two internal striae (yellow arrowheads) per interridge (bar $=30 \mu \mathrm{m})$. D-F (case 2; Masson-Goldner trichrome staining). D, Worm sections in the inflammatory infiltrate (bar $=600 \mu \mathrm{m})$. E, Oblique and sublongitudinal section showing the cuticle with ridges (black arrows) and two striae (reddish) (yellow arrowheads) per interridge, and muscles cells (bar $=50 \mu \mathrm{m}$ ). F, Transverse section in anterior part with narrow lateral chord, developed muscle cells, thin intestine and two uteri (bar $=50 \mu \mathrm{m})$.

samples was made available for further examination and confirmation of the diagnosis (see Results section).

In both cases, the presence of dogs living in the same area as that of the patient was reported. In addition, for case 2, cats, donkeys, sheep, goats and cattle were also present in the setting. No history of insect bites was reported. Written informed consent was obtained from the patients for publication of this report and any accompanying images.

\section{Morphological and molecular identification}

Both samples were fixed in $10 \%$ buffered formalin solution ( $\mathrm{pH}$ 7.4), paraffin embedded and routinely processed for light microscopy. Sections of $5 \mu \mathrm{m}$ thickness were stained with haematoxylin and eosin (HE) and, in case 2, also with Masson Goldner trichrome for a clearer definition of the parasitological and morphological features.
The histological preparations were morphologically examined and photographed. The paraffin blocks were eluted by the heat (case 1) or in xylol (case 2) and nematode fragments were recovered for morphological description (case 2, preserved in the Muséum National d'Histoire Naturelle collection, Paris, collection number (CN: $308 \mathrm{JW}$ ), or molecular identification (case 1). The diverse fragments (case 2) recovered from the paraffin block were cleared in lactophenol, observed, drawn and measured as described in Bain et al. [7].

During the study, particular attention was paid to the main diagnostic characters of the genus Onchocerca and its species. Briefly, the cuticle of female body in this genus is composed of two layers, the external with prominent transverse ridges, the internal with transverse striae; the shape of ridges (transverse section, undulated or not), the distance between ridges, the number of striae per inter- 
ridge are specific [29], as well as the ratio of the body diameter to the distances between ridges [11]. The female cuticle morphology of a species of Onchocerca is not present in the anterior $5 \mathrm{~mm}$ but it is formed progressively posteriorly. This feature is acquired during adult growth and in young females ridges are tiny and straight and striae are absent [29]. Other characters are the general shape of the body, straight or coiled, the presence/absence of a lateral cuticular thickening along the body, the shape and size of the lateral chords, the number and size of muscles per quadrant, the diameter of the intestine. When possible, other characters are analysed. Indeed, in Onchocerca the buccal cavity is tiny, the vulva is in the oesophageal region, the vagina simple without bends and sphincter; the oesophagus is divided or not, depending on the species [30].

For comparison with the present worms, specimens of O. lupi from dogs in Greece (recovered by A. Komnenou and loaned by M.L. Eberhard; MNHN collections, Paris, number $309 \mathrm{JW})$ and histological sections of infested sclera from a dog in Hungary (loaned by T. Sreter, MNHN number $400 \mathrm{JW}$ ) were studied.

The molecular diagnosis was performed on the specimen from case 2 by genomic extraction and amplification of mitochondrial cytochrome $c$ oxidase subunit 1 ( $\operatorname{cox} 1)$ and $12 \mathrm{~S}$ genes as described elsewhere [24].

\section{Results}

Case 1 from Turkey was due to a large completely developed female tightly coiled in the subconjunctival connective tissue (Figure 1A). It was easily identified as O. lupi. The cuticle was composed of an external layer bearing prominent, transverse ridges, rounded and undulated, spaced from 13 to $30 \mu \mathrm{m}$ (mean $21.3 \mu \mathrm{m}$ ) and an internal layer with transverse striae (Figure 1B, C). These morphological characters are typical of female filarioids belonging to the Onchocerca genus and are different from those of $D$. repens which bear longitudinal cuticular ridges [31].

Case 2, from Tunisia (308 JW) was caused by an immature adult female worm. Several coiled fragments $(9.6 \mathrm{~mm}$ long) were recovered from the paraffin block including one anterior (Figure 1D, 2A). The filarial nematode presented a rounded head ( $42 \mu \mathrm{m}$ wide), with four externolabial papillae and four more posterior cephalic papillae (Figure 2C). The buccal cavity was tiny, the $670 \mu \mathrm{m}$ long oesophagus had no distinct glandular part. The body width at the oesophageal-intestinal junction was $80 \mu \mathrm{m}$ and the vulva was $580 \mu \mathrm{m}$ from the head and the vagina was simple without bends and chamber (Figure 2B). The cuticle was smooth in the anterior part and the external ridges appeared progressively when the cuticle was $10 \mu \mathrm{m}$ thick and the worm $230 \mu \mathrm{m}$ wide (Figures 1E, 2D, 2E).

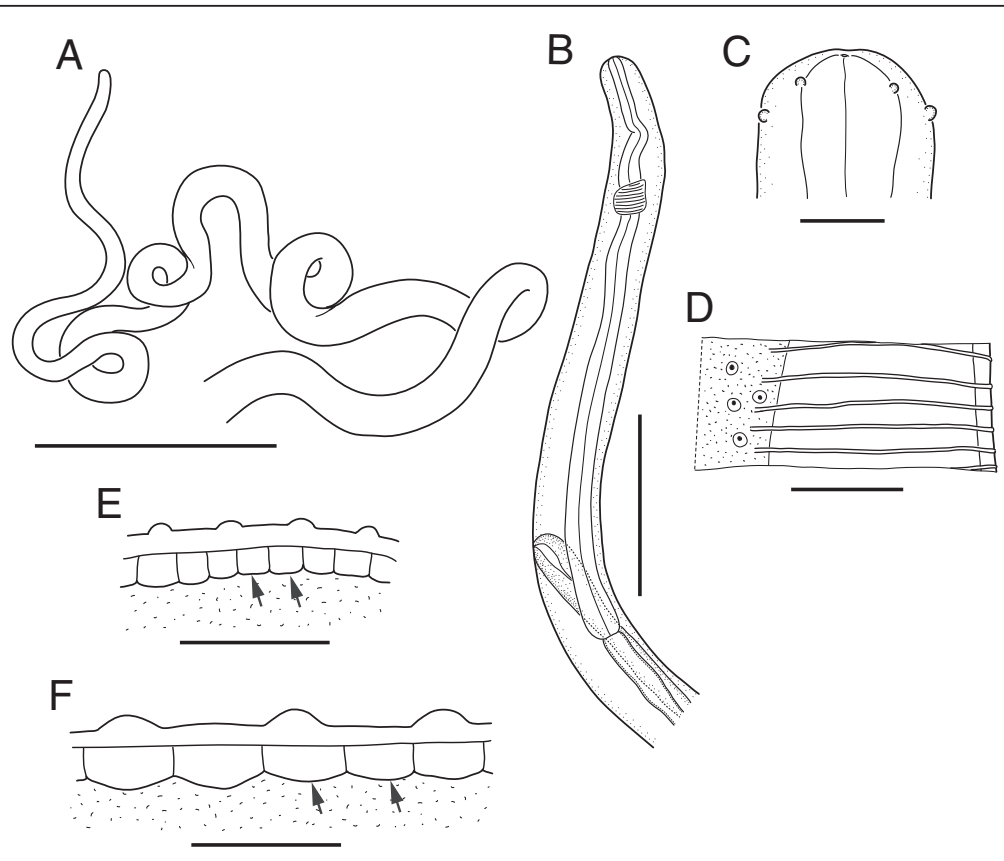

Figure 2 A-E (case 2) Immature female $(C N=308 \mathrm{JW})$ extracted from the paraffin block. A, Anterior coiled fragment of female $(\mathrm{bar}=1000 \mu \mathrm{m}) . \mathrm{B}$, Anterior region with oesophagus and vulva, left lateral view (bar $=200 \mu \mathrm{m})$. C, Head, lateral view (bar $=20 \mu \mathrm{m})$. D, Detail of cuticle with straight ridges interrupted at the lateral chord, body width at that level $230 \mu \mathrm{m}(\mathrm{bar}=50 \mu \mathrm{m})$. E, Detail of cuticle with external layer and ridges and internal layer and striae (arrows), width at that level $265 \mu \mathrm{m}(\mathrm{bar}=30 \mu \mathrm{m})$. F, O. lupi from a dog from Greece (CN = $309 \mathrm{JW})$, cuticle of a mature female with ridges and striae (arrows), width of body at that level $180 \mu \mathrm{m}$ (bar $=30 \mu \mathrm{m})$. 
The ridges were thin and straight, $12-40 \mu \mathrm{m}$ apart, interrupted along the lateral sides of the body; their apices were rounded. An external and an internal layer of cuticle were identified and two internal transverse striae per interridge were observed on a segment of worm $275 \mu \mathrm{m}$ wide (Figure 2E). On histological sections, ridges similar to the nematode from case 1 were observed (Figure 1E); other morphological features were the high density of worm sections in the tissue infected, suggestive of a tightly coiled body, the cuticle with a constant diameter (not thickened laterally, Figure 1D). On sections, lateral hypodermal chords (thick and narrow in the anterior part, flat and wide in the mid part), 5-6 rather thick muscle cells per quadrant, thin intestine and two uteri were evident (Figure 1 D-F).

All features observed fit previous descriptions [8,9,22], and with our observations on O. lupi from Greece (309 JW, Figure 2F) and Hungary (400 JW). Particularly, the cuticular ridges with round apices, the two striae per interigde, the shape and the size of the lateral hypodermal chords and the number and the height of the muscle cells were similar. However, in the absence of the characteristic small microfilariae (about $100 \mu \mathrm{m}$ O. lupi), two other Onchocerca species, O. volvulus and O. lienalis, which also present two striae per interidge, were also considered [11]. O. volvulus is distinct with wider and thicker lateral chords and more reduced muscles cells [32]. O. lienalis is characterized by ridges and striae developed in correspondence with the posterior extremity of the body only, the cuticle surface is scalloped, the lateral chords are narrow and thick all along the body, and the muscle cells are thicker; in addition, the anterior female region is almost twice as thin [32]. Another Onchocerca species, namely Onchocerca raillieti, which might be present in local donkeys and possible agent of zoonosis, differs from the nematode identified herein in that the former is characterized by a divided and long oesophagus, as well as cuticle presenting internal striae but no external ridges [32].

In accordance with the morphological identification, the BLAST analysis of $\operatorname{cox} 1$ and $12 \mathrm{~S}$ genes of the nematode from case 1, showed a 99-100\% nucleotide homology with sequences of $O$. lupi available in GenBank (cox1: HQ207644, AJ415417, EF521409, EF5214101; 12 S rDNA: GU365879, HQ207645).

\section{Discussion}

Following the first evidence of human zoonotic infestation by $O$. lupi [24] this study indicates that it was not an occasional finding. Indeed, case 1 (from a different geographical area than the first report in Turkey) and case 2 (from an area in Africa) came from places where O. lupi had never been previously reported. In both cases no information on the occurrence of the infestation in dogs, the proper host for $O$. lupi, is available indicating that parasitological studies should be carried out to estimate the actual distribution of this parasite circulating in dog populations. Considering the narrow host range of parasites belonging to the Onchocerca genus [6,30,33], the fact that $O$. lupi infects both humans and dogs suggests that, if these two species share the same environment, humans may be at risk of infestation. Unfortunately, up until now infestation by $O$. lupi was reported only on occasions where dogs presented clinical signs (e.g., ocular subscleral lesions). In contrast, no extensive cognitive surveys based on the diagnosis of microfilariae in skin samples are available, most likely reflecting an underestimation of the actual distribution of this parasitic disease. Definitive evidence that $O$. lupi may infest humans, and thus the zoonotic role of this nematode, are represented by the fact that the nematode from case 1 was a mature female nematode. This is inferred not only by the measurements of the body fragments and by the morphological characteristics of the cuticle.

The results here presented also suggest that this zoonotic infestation is more diffused than previously believed, being probably misdiagnosed with other helminths infesting human eyes such as Dirofilaria spp.. Definitively, $O$. lupi should be considered in the differential etiological diagnosis of nematodes in human eyes. The morphological distinctive characters of female nematodes allow a straightforward identification since $O$. lupi presents thick cuticle composed of an external layer bearing prominent, undulated annular ridges and an internal layer with transverse striae. These morphological features are not present in the species suspected initially to be agents of these cases; $D$. repens has longitudinal crests and $D$. immitis has a smooth cuticle. Without any doubt a proper preparation of samples is pivotal for achieving an etiological diagnosis of parasites extracted from human eyes. Physicians and ophthalmologists should be aware that before treating samples in formalin for further histological analysis or simply for preservation, they should save a small amount of material in ethanol so that it can be processed molecularly. Indeed, a specific molecular assay was useful for case 1 which provided further confirmatory evidence on the etiological diagnosis. Recently, an integrated DNA barcoding of $\operatorname{cox} 1$ and $12 \mathrm{~S}$ mitochondrial markers and morphological approaches were shown to be powerful tools for the taxonomic identification of many filarioid species, including O. lupi $[22,24]$, even if small nematode fragments were available [34]. Additionally, a test based on the detection of circulating antibodies could be of importance to better understand the occurrence of $O$. lupi infestation in human patients living in, or who have travelled to endemic areas. Indeed, although helminths infesting the human eyes or the surrounding tissues should be removed by surgical procedures, therefore allowing diagnoses to be 
achieved by means of sample examination, the detection of antibodies against $O$. lupi could be indicative of the infestation, as in the case of O. volvulus [35].

\section{Conclusion}

The role played by dogs as reservoirs of O. lupi needs to be assessed in order to establish their activity as primary definitive hosts and to assess the risk for human infestation in a given area. Accordingly, knowledge on the biological vector of this infestation will contribute to better understanding of the transmission patterns and the seasonality of this zoonotic infestation.

\section{Competing interest}

The authors declare that they have no competing interest.

\section{Acknowledgments}

We thank A. Komnenou (Ophthalmologist at the Faculty of Veterinary Medicine, Thessaloniki, Greece), M.L. Eberhard (Division of Parasitic Diseases and Malaria, Centres for Disease Control and Prevention, Atlanta, Georgia), T. Sreter (Department of Parasitology and Zoology, Faculty of Veterinary Science, Szent István University, Budapest, Hungary) for providing specimens of O. lupi. This work was possible also thanks to the contribution of Prof. Silvio Pampiglione (Born in Rome the 18th, April, 1925; Death in Bologna the 5th, October 2008) who was involved in some discussions on the case from Tunisia. Authors thank Novartis Animal Health, Inc for supporting the publication costs of this study.

\section{Author details}

'Dipartimento di Sanità Pubblica Veterinaria e Zootecnia, Università degli Studi di Bari, Bari Valenzano, Italy. ²Departamento de Imunologia, Centro de Pesquisas Aggeu Magalhães (Fiocruz-PE), PernambucoRecife, Brazil.

${ }^{3}$ Department of Ophtalmology, Istanbul University Faculty of Medicine, Istanbul, Turkey. ${ }^{4}$ Department of Pathology, Istanbul University Faculty of Medicine, Istanbul, Turkey. ${ }^{5}$ Department of Clinical Microbiology, Istanbul University Faculty of Medicine, Istanbul, Turkey. ${ }^{6}$ Dipartimento di Sanità Pubblica e Patologia Animale, Università degli Studi di Bologna, Ozzano EmiliaBologna, Italy. 7 Laboratoire d'Anatomie et de Cytologie Pathologiques, CHU Farhat Hasched, Sousse, Tunisia. ${ }^{8}$ Institute of Biodiversity and Ecosystem Research, Bulgarian Academy of Sciences, Sofia, Bulgaria. ${ }^{9}$ Muséum National d'Histoire Naturelle, UMR 7205 CNRS, Parasitologie Comparée, Paris, France.

\section{Authors' contributions}

$\mathrm{DO}, \mathrm{OB}$ conceived the research, contributed with data analysis and interpretation and wrote the first draft of the manuscript and contributed the morphological examination. OB, YM made drawings. FDT contributed with data analysis, interpretation and revision of the manuscript. ZC, BY, NB, OBB, $A G, T M$ collected samples and were responsible for all ophthalmologic aspects and the nematode collection. All authors read and approved the final version of the manuscript.

\section{Received: 8 April 2012 Accepted: 27 April 2012}

Published: 27 April 2012

\section{References}

1. Otranto D, Eberhard ML: Zoonotic helminths affecting the human eye. Parasit Vectors 2011, 4:41.

2. Basáñez MG, Pion SD, Churcher TS, Breitling LP, Little MP, Boussinesq M: River blindness: a success story under threat? PLoS Med 2006, 3:e371.

3. Richards FO Jr, Boatin B, Sauerbrey M, Sékétéli A: Control of onchocerciasis today: status and challenges. Trends Parasitol 2001, 7:558-563.

4. Botero D, Aguledo LM, Uribe FU, Esslinger JH, Beaver PC: Intracoular filarial, a Loaina species, from man in Colombia. Am J Trop Med Hyg 1984, 33:578-582.

5. Beaver PC: Intraocular filariasis: a brief review. Am J Trop Med Hyg 1989, 40:40-45.
6. Orihel TC, Eberhard ML: Zoonotic filariasis. Clin Microbiol Rev 1998, 11:366-381.

7. Bain O, Otranto D, Diniz DG, dos Santos Nascimento J, de Pinto Oliveira N, De Almeida Negrão Frota NI, de Almeida Negrão Frota R, de Almeida Negrão Frota L, Dantas-Torres F, Frota de Almeida, Sobrinho E: Human intraocular filariasis caused by Pelecitus sp., Brazil. Emerg Infect Dis 2011, 17:867-869.

8. Rodonaja TE: A new species of Nematode, Onchocerca lupi n. sp., from Canis lupus cubanensis. Soobshchenyia Akad. Nauk Gruzinskoy SSR 1967, 45:715-719.

9. Demiaszkiewicz AW, Matsaberidze GV, Kvavadze ES: The female of Onchocerca lupi Rodonaja, 1967 under a scanning electron microscope. Acta Parasitol 1991, 36:183-186

10. Demiaszkiewicz AW, Matsaberidze GV: New details on the morphology of Onchocerca lupi (Nematoda, Filarioidea). Wiad Parazytol 1991, 37:255-259.

11. Egyed Z, Sréter T, Széll Z, Beszteri B, Oravecz, Márialigeti K, Varga I: Morphologic and genetic characterization of Onchocerca lupi infesting dogs. Vet Parasitol 2001, 102:309-319.

12. Széll Z, Erdélyi I, Sréter T, Albert M, Varga I: Canine ocular onchocercosis in Hungary. Vet Parasitol 2001, 97:245-251.

13. Komnenou A, Eberhard ML, Kaldrymidou E, Tsalie E, Dessiris A: Subconjunctival filariasis due to Onchocerca sp. in dogs: report of 23 cases in Greece. Vet Ophthalmol 2002, 5:119-126.

14. Hermosilla A, Hetzel U, Bausch M, Grübl J, Bauer C: First autochthonous case of canine ocular onchocercosis in Germany. Vet Rec 2005, 154:450-452.

15. Sréter-Lancz Z, Széll Z, Sréter T: Molecular genetic comparison of Onchocerca sp. infecting dogs in Europe with other spirurid nematodes including Onchocerca lienalis. Vet Parasitol 2007, 148:365-370.

16. Faísca P, Morales-Hojas R, Alves M, Gomes J, Botelho M, Melo M, Xufre A: A case of canine ocular onchocercosis in Portugal. Vet Ophthalmol 2010, 13:117-121.

17. Orihel TC, Ash LR, Holshuh HJ, Santenelli S: Onchocerciasis in a California dog. Am J Trop Med Hyg 1991, 44:513-517.

18. Gardiner $\mathrm{CH}$, Dick EJ Jr, Meininger AC, Lozano-Alarcón F, Jackson P: Onchocerciasis in two dogs. J Am Vet Med Assoc 1993, 203:828-830.

19. Eberhard ML, Ortega Y, Dial S, Schiller CA, Sears AW, Greiner E: Ocular Onchocerca infections in western United States. Vet Parasitol 2000, 90:333-338.

20. Zarfoss MK, Dubielzig RR, Eberhard ML, Schmidt KS: Canine ocular onchocerciasis in the United States: two new cases and a review of the literature. Vet Ophthalmol 2005, 8:51-57.

21. Labelle AL, Daniels JB, Dix M, Labelle P: Onchocerca lupi causing ocular disease in two cats. Vet Ophthalmol 2011, 14(Suppl 1):105-110.

22. Sréter T, Széll Z: Onchocercosis: a newly recognized disease in dogs. Vet Parasitol 2008, 151:1-13.

23. Sréter T, Széll Z, Egyed Z, Varga I: Subconjunctival zoonotic onchocercosis in man: aberrant infection with Onchocerca lupi? Ann Trop Med Parasitol 2002, 96:497-502.

24. Otranto D, Sakru N, Testini G, Gürlü VP, Yakar K, Lia RP, Dantas-Torres F, Bain O: Case report: First evidence of human zoonotic infection by Onchocerca lupi (Spirurida, Onchocercidae). Am J Trop Med Hyg 2011, 84:55-58.

25. Uni S, Boda T, Daisaku K, Ikura Y, Maruyama H: Zoonotic filariasis caused by Onchocerca dewittei japonica in a resident of Hiroshima Prefecture, Honshu, Japan. Parasitol Int 2010, 59:477-480.

26. Burr WE Jr, Brown MF, Eberhard ML: Zoonotic Onchocerca (Nematoda: Filarioidea) in the cornea of a Colorado resident. Ophthalmology 1998, 105:1494-1497.

27. Koehsler M, Soleiman A, Aspöck H, Auer H, Walochnik J: Onchocerca jakutensis 271 filariasis in humans. Emerg Infect Dis 2007, 13:1749-1752.

28. Ziadi S, Trimèche M, Mestiri S, Mokni M, Trabelsi A, Ben Abdelkader A, Ben Said M, Ben Hadj Hamida F, Korbi S: La dirofilariose sous-conjonctivale humaine. A' propos de deux cas tunisiens. J Fr Ophtalmol 2005, 28:e2.

29. Takaoka H, Bain O, Uni S, Korenaga M, Kozek WJ, Shiraasaka C, Aoki C, Otsuka Y, Fukuda M, Eshita Y, Daa T: Zoonotic onchocerciasis caused by a parasite from wild boar in Oita, Japan: a comprehensive analysis of morphological characteristics of the worms for its diagnosis. Parasite 2004, 11:285-292.

30. Uni S, Bain O, Agatsuma T, Harada M, Torii H, Fukuda M, Takaoka H: Onchocerca eberhardi n. sp. (Nematoda: Filarioidea) from sika deer in 
Japan; relationships between species parasitic in cervids and bovids in the Holarctic region. Parasite 2007, 14:199-211.

31. Anderson RC: Description and relationships of Dirofilaria ursi Yamaguti, 1941, and a review of the genus Dirofilaria Railliet and Henry, 1911. Trans Roy Can Inst 1952, 29:35-65.

32. Bain O: Le genre Onchocerca: hypothèses sur son évolution et clé dichotomique des espèces. Annales Ann Parasitol Hum Comp 1980, 56:503-526.

33. Eberhard ML, Dickerson JW, Tsang VC, Walker EM, Ottesen EA,

Chandrashekar R, Weil GJ, Trpis M, Strobert E, Constantinidis I, Swenson RB: Onchocerca volvulus: parasitologic and serologic responses in experimentally infected chimpanzees and mangabey monkeys. Exp Parasitol 1995, 80:454-462.

34. Ferri E, Barbuto M, Bain O, Galimberti A, Uni S, Guerrero R, Ferté H, Bandi C Martin C, Casiraghi M: Integrated taxonomy: traditional approach and DNA barcoding for the identification of filarioid worms and related parasites (Nematoda). Front Zool 2009, 6:1.

35. Udall DN: Recent updates on onchocerciasis: diagnosis and treatment. Clin Infect Dis 2007, 44:53-60.

doi:10.1186/1756-3305-5-84

Cite this article as: Otranto et al: Human ocular filariasis: further evidence on the zoonotic role of Onchocerca lupi . Parasites \& Vectors 2012 5:84.

\section{Submit your next manuscript to BioMed Central and take full advantage of:}

- Convenient online submission

- Thorough peer review

- No space constraints or color figure charges

- Immediate publication on acceptance

- Inclusion in PubMed, CAS, Scopus and Google Scholar

- Research which is freely available for redistribution 